\title{
The Confirmatory Factor Analysis of Secondary School Teachers' Contextual Performance Structure in Mainland China
}

\author{
Zhongfeng Hu1, Yihuan Jiang1, Qimei Li² \\ ${ }^{1}$ School of Public Administration, South China Normal University, Guangzhou, China \\ ${ }^{2}$ Shunde Li Zhaoji Middle School, Foshan, China \\ Email: Huzhongfe@163.com
}

Received 3 June 2015; accepted 4 July 2015; published 8 July 2015

Copyright (C) 2015 by authors and Scientific Research Publishing Inc.

This work is licensed under the Creative Commons Attribution International License (CC BY). http://creativecommons.org/licenses/by/4.0/

c) (i) Open Access

\section{Abstract}

The contextual performance has drawn much attention from some growing study bodies, and western researchers have proposed the dimensions of it. However, few empirical researches have been conducted on this topic in mainland China. This study explored the structure and developed the scale of Chinese secondary school teachers' contextual performance. The results indicate that the scale contains four dimensions in Chinese context, which are Occupational Morality, Self-development, Harmonious Cooperation, and Organizational Identification. The study shows that the four dimensions in Chinese context are different from those of western researches.

\section{Keywords}

Contextual Performance, Occupational Morality, Self-Development, Harmonious Cooperation, Organizational Identification

\section{Introduction}

Over the past decades, many empirical studies of psychology and management have indicated that individuals have different ways of making contributions in realizing the shared organizational goals. Only after researchers of job performance distinguished between task performance and contextual performance (Borman \& Motowidlo, 1993) did we begin to attach importance to the research of teachers' contextual performance in China. Some studies pointed out that the performance assessment in China was easily impacted by subjective feelings and interpersonal relationships. Therefore, contextual performance tends to be prior to task performance.

Teachers' job performance which includes task performance and contextual performance (Zhou \& Wang, 
1999) is the important content of teachers’ performance evaluation and the promotion of teachers’ professional development. At present, there are many researches on task performance, but few on contextual performance. Contextual performance itself is very important especially in China, but there is almost no research on contextual performance of secondary school teachers. Therefore, this study has great value with its practical significance. The structure of contextual performance proposed and testified in this study is helpful to both deepen the understanding and enrich the theory of contextual performance. The structure of contextual performance which serves as a theoretical basis is a very essential part of contextual performance evaluation.

\section{The Connotation and the Structure of Contextual Performance}

The contextual performance is not direct productivity or service activity, but can provide these activities with a wide range of organizational, social and psychological support. It is viewed as discretionary behaviors not formally required by any particular job, and it mainly consists of voluntary acts, organizational citizenship behaviors, pro-organizational behaviors, organizational dedications, and behaviors irrelevant to specific tasks, such as willingness to do extra work and to help colleagues and so on. It can promote not only task performance but also communication in the organization, while it has the lubrication effect on the communication of society, reduces the emotional response of tension, and thereby enhances the effectiveness of the whole organization (Borman \& Motowidlo, 1993).

A study proposed by Borman and Motowidlo indicates that the contextual performance includes five aspects (Borman \& Motowidlo, 1993). Firstly, members are able to maintain high enthusiasm and make extra effort to successfully complete work tasks; secondly, members voluntarily do extra work beyond their duty range; thirdly, they help and cooperate; fourthly, they observe the provisions and procedures of the organization; and fifthly, they approve, support and maintain the goals of the organization. Based on the performance assessment of 975 aviation mechanics which was conducted by their direct managers, a study suggested that contextual performance wasn't worthy of discussion without considering interpersonal promotion and duty dedication. Task performance could be separated from interpersonal promotion, but not from duty dedication (Van Scotter \& Motowidlo, 1996). Hence, they concluded that task performance should include the elements of tasks and the motive to efficiently complete tasks, while contextual performance should include interpersonal ability, maintenance of good work relationship and motive to help others complete tasks. Some studies proposed that the contextual performance should include three aspects: to co-operate with others, to make extra efforts and to observe the regulations of the organization (Conway, 1999). Some other scholars considered that the characteristics of the contextual performance could be summarized as follows: dealing with work stress and working with responsibility (Johnson, 2001), making suggestions to improve the organization, putting forth constructive ideas, and convincing others to follow suggestions and guidance (LePine \& Van Dyne, 2001).

Coleman and Borman differentiated 27 behaviors of contextual performance and finally classified them into a simple model of 3 aspects, namely civic performance of interpersonal relationship, organizational citizen performance, and work responsibility (Coleman, 2000).

Jingli Fan from Chinese University of Hong Kong (1997) investigated the contextual performance of Chinese enterprises, and found that contextual performance could be assessed in a similar way to assessment of concentric circles, with individuals, groups, organizations and society as different rings. Thus they put forth a structure of 11 dimensions covering Chinese and western characteristics.

\section{The Connotation of Teachers' Contextual Performance}

Teachers' contextual performance refers to teachers' social and psychological behaviors consistent with their educational goal during teaching processes. They are voluntary behaviors beyond the role standard of teachers, under the condition of non-basic work requirements, and not relevant to specific tasks (Cai, 2002). Teachers' context performance is active, positive and altruism. It is not only beneficial to students and colleagues, but also helpful to the improvement of the overall efficiency of schools. Teachers' contextual performance also plays a positive role in forming a good school culture, maintaining interpersonal harmony and enhancing teachers' sense of identity and perception of affiliation to the school.

At present, from literature on the structure of teachers' performance, we find a large proportion of speculative studies with little on secondary school teachers' contextual performance. As far as attainable foreign literature is concerned, stress has only fallen on teachers' task performance, and still absent is the research on teachers' con- 
textual performance. Therefore, this paper aims at the construction of secondary school teachers' contextual performance in Chinese cultural background, offering reference to school administrators to improve assessment of teachers' performance.

\section{The Development of the Contextual Performance Scale for Secondary School Teachers}

\subsection{Purpose}

The primary purpose of this part is to develop the contextual performance scale for secondary school teachers for the further empirical research.

\subsection{Methodology}

Firstly, we studied domestic and foreign literature of contextual performance researches, did interviews with many secondary school teachers, clarified the connotation of secondary school teachers' contextual performance, and collected a list of items about contextual performance behaviors through open-ended questionnaires. Secondly, based on the collected information, an initial edition of the scale was formed. Thirdly, the formal secondary school teachers' contextual performance scale was drawn up according to statistical analyses.

\subsection{Procedure}

\subsubsection{Literature Review}

The literature review consisted of two parts: firstly confining the connotation of secondary school teachers' contextual performance, and secondly sorting out the present researches on contextual performance.

\subsubsection{Interviews}

Researchers interviewed some teachers of different subjects at different schools, as well as a smaller group of students and some parents. Each interview was made up of two parts: one focused on the connotation of contextual performance, the other on some specific behaviors of it. Firstly, the researchers asked the interviewees: "In your opinion, what behaviors should an excellent teacher have?” Secondly, the researchers introduced the present study of contextual performance from the literature and requested the interviewees to evaluate those ideas. Finally, the interviewed teachers were asked to make a list of behaviors in response to the following question, "In your daily work, are there voluntary behaviors which are good to teaching activities, but within neither official duties nor the labor payment contract?" Considering the abstractness and complexity of the concept of contextual performance, the interviewers further asked interviewees additional questions to achieve a better understanding of how they perceived contextual performance.

\subsubsection{Open-Ended Questionnaire Survey}

Firstly, with reference to existing domestic and foreign studies, the connotation of secondary school teachers' contextual performance was defined. Based on this connotation, the researchers carried out an open-ended questionnaire survey to ask the respondents to list out at least 10 items of contextual performance behaviors or characters according to their understanding and work experience.

Secondly, the results of interviews and the open-ended questionnaires were collected and analyzed through keyword method to get items which were then subjected to evaluation. After discussion with some experienced secondary teachers, the researchers organized the items by combining repeated items, separating items with double or triple meanings, sorting out items with re-appearance, and finally reached a preliminary investigation scale of secondary school teachers' contextual performance with a total number of 37 items. Likert five-point scoring method was adopted in this scale, from "totally disagree" to "totally agree".

Finally, in order to confirm that all the questionnaire statements are clear and able to reflect the actual situations in secondary schools, we asked 10 teachers with different academic backgrounds and qualifications for comments and suggestions so as to make necessary modifications to the expressions.

\subsubsection{Results}

Participants were full-time secondary teachers from Guangzhou and Foshan. 110 questionnaires were distributed, 
of which 97 completed surveys were recalled, making the effective recovery rate $88 \%$. We applied exploratory factor analysis method for statistical analysis, which was supported by SPSS 13.0.

Before exploratory factor analysis, we tested fitting degree of factor analysis, and the result showed that the value of KMO sample was 0.825, Bartlett's ball chi-square test value was 1981.658, the degrees of freedom was 666 , and the significant level was less than 0.001 , meaning statistically very significant. All these statistics indicated that the data were suitable for factor analysis.

In the exploratory factor analysis, we deleted 3 types of items, which were of low communality and factor loading, which were of high cross-factor loading, and which fell into the same factor but carried meanings in different ranges. Thus a total of 18 items were retained in the formal scale with a variance explanation rate of 69.307\%.

\section{The Exploratory Factor Analysis of Teachers' Contextual Performance}

\subsection{Purpose}

The formal questionnaire for the contextual performance scale was conducted with a great number of secondary school teachers, and exploratory factor analysis was adopted for the survey data.

\subsection{Methodology}

Participants were full-time secondary school teachers from Guangdong and Jiangxi province. 190 surveys were distributed, of which 173 completed surveys were received at a recovery rate of $93.7 \%$.

We applied exploratory factor analysis method in this study, which was also supported by SPSS 13.0.

\subsection{Procedure}

The anonymous questionnaire was distributed to participants by agents. Before distribution, we carefully made agents clearly understand the purpose, significance, process, and precautious matter of the test.

\subsection{Results}

Before exploratory factor analysis, we tested fitting degree of factor analysis, and the data showed that the value of KMO sample was 0.826, Bartlett's ball chi-square test value was 1113.356, the degrees of freedom was 120, and the significant level was less than 0.001 , reaching a very significant level. All these indicated that the data were suitable for factor analysis.

Principal component analysis was adopted to extract factors in the exploratory factor analysis, varimax factor rotation method was applied to select factors with eigenvalue over 1, and the Scree plot was referred to in determining the factors. The deleting principles were the same as in the formal research. Finally, we deleted 2 items and applied factor analysis to the remaining 16 items.

The results have shown that the structure of secondary school teachers' contextual performance is a clear structure of 4 dimensions, namely, Occupational Morality, Self-development, Harmonious Cooperation and Organizational Identification, together accounting for $58.234 \%$ of the total variance (see Table 1 ).

\section{Occupational Morality}

The main contents of this dimension include teachers' behaviors to help students with their study and school life, to help new students adapt themselves to school environment as soon as possible, to care for teachers' own images, speeches and behaviors, which can set models for their students, and to pay attention to the overall development of students in teaching activities.

\section{Self-Development}

This dimension includes making use of spare time to learn work-related new knowledge and skills, trying and exploring new teaching methods, and actively taking part in educational scientific researches like school-based curriculum, research applications and other related activities.

\section{Harmonious Cooperation}

This dimension includes teachers' praises and congratulations on colleagues who are awarded with honors, willingness to shoulder the work of colleagues when they need help, activeness to discuss and communicate with colleagues on teaching and classroom management experience, and willingness to help new colleagues. 
Table 1. The result of factor analysis of the questionnaire.

\begin{tabular}{|c|c|c|c|c|}
\hline \multirow{2}{*}{ Item } & \multicolumn{4}{|c|}{ Loading } \\
\hline & $\mathrm{HC}$ & OM & SD & OI \\
\hline
\end{tabular}

T13. I am glad to share my teaching experience with colleagues.

0.78

T12. I am willing to shoulder the work of my colleagues when they are taken away by other things.

T11. Even when it is possible, I do not want to help to solve the misunderstandings and conflicts between colleagues.

T15. I am pleased to help new colleagues.

T14. I often discuss and communicate with colleagues about teaching and classroom management.

T9. I can give my praise and congratulations to colleagues when they are awarded honors.

T2. I like to help new students to adapt themselves to school environment as soon as possible.

T3. I don't care about the modeling effect of my own image, behaviors, and speech on students.

T4. I am devoted to the overall development of students in teaching activities.

T1. I like to voluntarily help students when they encounter difficulties in studies or in life.

T6. I wouldn't like to explore and try new teaching methods.

T7. I often actively take part in school-based curriculum, research applications and other related educational activities.

0.78

0.61

0.59

0.52

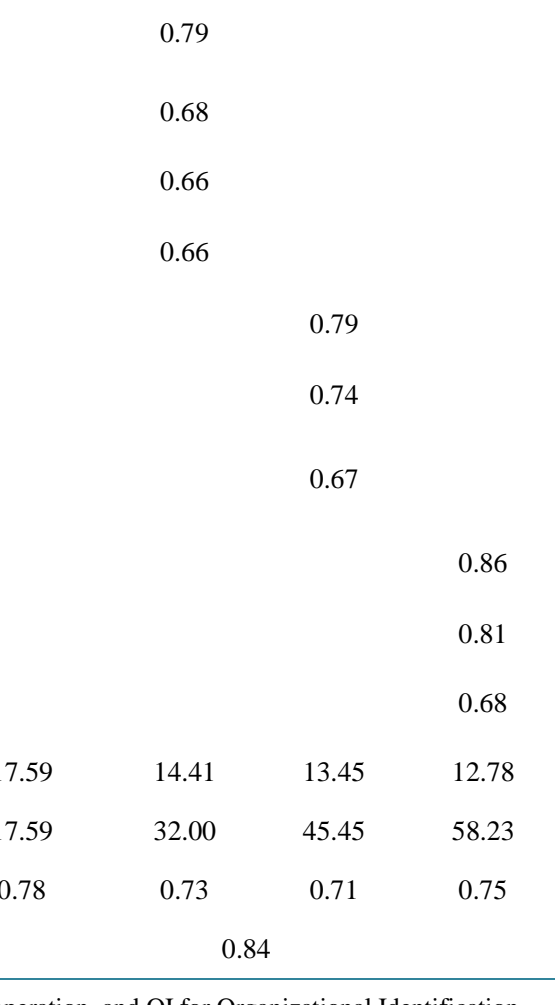

T5. I like to make use of my spare time to learn work-related new knowledge and skills.

T17. When friends ask me about my school, I will be very proud to introduce it to them.

T16. I often make effort to introduce or publicize the merits of my school.

T18. I don't put forward constructive suggestions for school-related departments for improvement.

Variance Explanation \%

Total Variance Explanation \%

Reliability of Each Factor

Total Reliability

Note: OM is short for Occupational Morality, SD for Self-development, HC for Harmonious Cooperation, and OI for Organizational Identification.

\section{Organizational Identification}

This dimension includes teachers' making effort to introduce or publicize the merits of their school, and to put forth constructive suggestions for school-related departments for improvement.

\section{The Confirmatory Factor Analysis of Teachers' Contextual Performance}

\subsection{Purpose}

The main purpose of this part is to confirm the results from the exploratory factor analysis, and to verify the 4-dimensioned structure of secondary school teachers' contextual performance.

\subsection{Method}

Participants were full-time secondary teachers from 10 schools in Guangdong and Jiangxi province. 450 surveys 
were distributed, of which 413 completed ones were received at a recovery rate of 91.78\%. Participants were selected in consideration of their ages, teaching subjects, qualifications, and teaching ages. Among the valid participants, 30.1\% were below 25 years old, and 37.6\% ranging from 25 to 35 years old; $46.2 \%$ had work experience of less than 5 years, $20.8 \%$ about 6 to 10 year, and 32\% over 11 years.

We applied confirmatory factor analysis for statistical analysis which was technically supported by Lisrel 8.50 .

\subsection{Hypothesis}

The Hypothesis in this study is that the contextual performance construction is a 4-dimensioned model. The competitive models included a 3-dimensioned model, a 2-dimensioned model and a single-dimensioned one.

\section{H1: A 4-dimensioned model}

As a result of the exploratory factor analysis, it's reasonable to assume that the secondary school teachers' contextual performance is a clear 4-dimensioned structure, including Occupational Morality, Self-development, Harmonious Cooperation and Organizational Identification.

\section{H2: A 3-dimensioned model}

Because both Occupational Morality and Self-development are tightly related to teaching and learning, it is possible to combine them into one dimension. In this hypothesis, the structure of secondary school teachers' contextual performance is a 3-dimensioned model.

\section{H3: A 2-dimensioned model}

Both Harmonious Cooperation and Organizational Identification have a relatively close relation with Organizational Identification, and may both belong to one single dimension, while Occupational Morality and Self-development another dimension. Thus, the structure of secondary school teachers' contextual performance is a 2-dimensioned model.

\section{H4: A single-dimensioned model}

Provided that the four factors can be put into one dimension, then the structure of secondary school teachers' contextual performance is a single-dimensioned model.

\subsection{Results}

The 4-dimensioned model met the requirements of confirmatory factor analysis. The other three models, i.e., the 3-dimensioned model, the 2-dimensioned model and the single-dimensioned one, didn't meet the standard. The data of RMSEA, AGFI, GFI, CFI, NNFI, NFI, RMR, PNFI are inferior to the corresponding standard. Compared with the rest models, the 4-dimensioned structure is a better one (see Table 2).

According to the theory of confirmatory factor analysis, when comparing the advantages and disadvantages of different models to decide which is better, we consider the loading of exogenous variables to latent variable, and the loading of exogenous variables to error variables. In general, the best model is found when the loading of exogenous variables to latent variable is higher, while the loading of exogenous variables to error variables is

Table 2. Data comparison of each contextual performance model.

\begin{tabular}{ccccc}
\hline & 4-Dimensioned Model & 3-Dimensioned Model & 2-Dimensioned Model & Single-Dimensioned Model \\
\hline$X^{2}$ & 199.62 & 260.24 & 421.10 & 1044.24 \\
$d f$ & 98 & 101 & 103 & 112 \\
$X^{2} / d f$ & 2.04 & 2.58 & 4.09 & 9.32 \\
$R M S E A$ & 0.06 & 0.08 & 0.12 & 0.20 \\
$A G F I$ & 0.88 & 0.84 & 0.76 & 0.53 \\
CFI & 0.91 & 0.86 & 0.73 & 0.20 \\
NNFI & 0.89 & 0.84 & 0.68 & 0.14 \\
$N F I$ & 0.84 & 0.80 & 0.67 & 0.19 \\
$R M R$ & 0.06 & 0.07 & 0.09 & 0.24 \\
PNFI & 0.69 & 0.67 & 0.58 & 0.18 \\
\hline
\end{tabular}


lower. The statistically suitable loading of exogenous variables to latent variable is supposed to range from 0.50 to 0.95 .

As can be seen from Figure 1, the loadings of each item (most exogenous variable) and factor (latent variable) range from 0.52 to 0.86 ; the interpretation rate of each item to its corresponding latent variable is larger; the loadings of exogenous variables to error variables are below 0.6 and are smaller than the loadings of the corresponding factor. All these figures indicate that the error is minor. Overall, the 4-dimensioned model is the best one in terms of confirmatory factor analysis.

\section{The Reliability and Validity of Teachers' Contextual Performance Scale}

\subsection{Purpose}

The main purpose of this part is to study whether or not the reliability and validity of the secondary school teachers' contextual performance scale can meet the requirements of psychological measurement.

\subsection{Method}

The study adopted the combination of the 173 valid participants for exploratory factor analysis and the 413 valid participants for confirmatory factor analysis as a sample, and conducted descriptive statistics, exploratory factor analysis and confirmatory factor analysis for this sample.

\subsection{Results}

\subsubsection{Reliability Analysis}

Internal consistency reliability is usually indicated by the Cronbach $\alpha$ coefficient. When the Cronbach $\alpha$ coeffi-

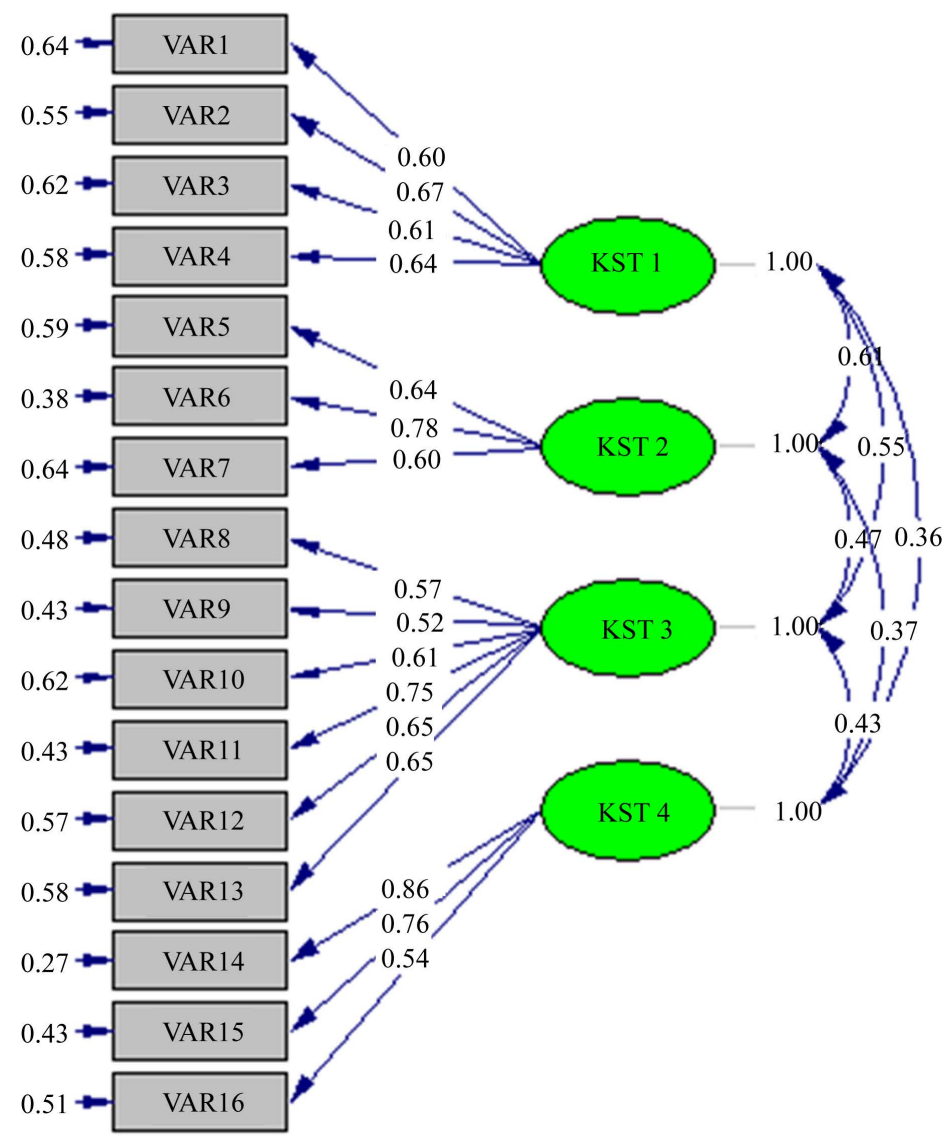

Figure 1. The loading of items and factors. 
cient is below 0.65 , the scale needs to be re-established (Wang, 2006). In this study, the total internal consistency coefficient of the questionnaire is 0.81 , and the reliability data of the four dimensions are all above 0.70 . The reliability of the questionnaire has satisfactorily met the requirements of psychology measurement (see Table 3).

\subsubsection{Validity Analysis}

Structure validity refers to how well a psychology test verifies the theoretical construct on which the test was based. The questionnaire of this study has a clear structure whose statistics completely meet the requirements of psychology measurement. The results are consistent with the theoretical construct. In addition, we can test the structure validity by observing the correlation between each item of the dimensions and the total scores of corresponding dimension. If each item from each dimension has a significant correlation with the total scores of the corresponding dimension, we can conclude that the internal homogeneity is good, and that the questionnaire has good validity (see Table 4).

\subsection{Results}

Through confirmatory factor analysis and exploratory factor analysis, we have found that the structure of secondary school teachers' contextual performance is a clear 4-dimensioned model, whose dimensions can be named Occupational Morality, Self-development, Harmonious Cooperation and Organizational Identification. We also have tested the reliability and validity of the scale and got satisfactory statistics to support the study.

\section{Discussion}

The structure of secondary school teachers' contextual performance (a 4-dimensioned model) in this study and the college teachers' contextual performance (a 3-dimensioned model) proposed by Yonghong Cai in 2002 overlap to some extent, while there are differences in between.

Firstly, both models contain the dimension of Occupational Morality, which is reflected by college teachers' recognizing and supporting the school goal and their own work, whereas reflected by secondary school teachers' concerning and helping students with their living and study.

Secondly, job dedication in the theory of the 3-dimensioned model includes teachers' care and love for students in the dimension of Self-development of the 4-dimensioned structure, but the former model does not emphasize self-innovation, which may be associated with the current basic education reform and development in our country. At present, the upsurge of educational scientific research has spread from universities, research institutes and other professional research institutions to the vast number of primary and secondary school teachers.

Table 3. The cronbach $\alpha$ coefficient of the secondary school teachers' contextual performance scale $(n=586)$.

\begin{tabular}{cccccc}
\hline Dimension & OM & SD & HC & OI & Whole Scale \\
\hline Cronbach $\alpha$ coefficient & 0.76 & 0.73 & 0.77 & 0.76 & 0.81 \\
\hline
\end{tabular}

Note: OM is short for Occupational Morality, SD for Self-development, HC for Harmonious Cooperation, and OI for Organizational Identification.

Table 4. The correlation between each item and the total scores of corresponding dimensions in the secondary school teachers' contextual performance scale.

\begin{tabular}{|c|c|c|c|c|}
\hline Item & Occupational Morality & Self-Development & Harmonious Cooperation & Organizational Identification \\
\hline Item 1 & $0.712^{* *}$ & $0.763 * *$ & $0.691 * *$ & $0.832 * *$ \\
\hline Item 2 & $0.806^{* *}$ & $0.821 * *$ & $0.666^{* *}$ & $0.835^{* *}$ \\
\hline Item 3 & $0.717 * *$ & $0.800 * *$ & $0.731 * *$ & $0.790 * *$ \\
\hline Item 4 & $0.727 * *$ & & $0.779 * *$ & \\
\hline Item 5 & & & $0.673 * *$ & \\
\hline Item 6 & & & $0.692 * *$ & \\
\hline
\end{tabular}

Note. 1 ) **signifies $p<0.01 ; 2$ ) "Item 1 ” refers to the first item in the specific dimension, "Item 2" the second, etc. 
The concept of educational research has become a driving force for sustainable development of teachers and schools. More and more "research-oriented teachers" begin to reflect the strengths and weaknesses of their own professional quality, hoping to explore the development of commonness and individuality of students through a system of educational scientific research, and to seek out the best way to improve themselves along with their students. Thus, both innovative education experiment and participation of educational scientific researches have become a trend among Chinese teachers.

Thirdly, Harmonious Cooperation in the 4-dimensioned structure overlaps Mutual Cooperation in the 3-dimensioned one. But the item of setting up a good relationship with parents is not obviously reflected in our study. In the pilot test study we have taken this item into consideration, but through interviews with secondary school teachers and factor analysis, it proved a lower loading than other items and the impact was not obvious. As regard to reasons, secondary school teachers of nowadays are generally in favor of effective communication between students, and expect to solve problems in communication with students instead of intervention from parents.

Fourthly, Organizational Identification of the 4-dimensioned model merges into Occupational Morality of the 3-dimensioned one, but there is lack of items about actively expressing viewpoints in the 4-dimensioned one.

\section{Conclusion}

The innovation of this research mainly includes: 1 ) The contextual performance of secondary school teachers is studied in the context of Chinese culture, thus the topic range of this research is innovative; 2) The combination of exploratory factor analysis and confirmatory factor analysis is used in the study, which could be classified as innovation in the research method; 3) The results of the research are different from other studies and some new ideas are provided in the concluding section.

\section{References}

Borman, W. C., \& Motowidlo, S. J. (1993). Expanding the Criterion Domain to Include Elements of Contextual Performance. In: N. Schmitt, \& W.C. Borman (Eds.), Personnel Selection in Organizations (pp. 71-98). San Francisco, CA: Jossey Bass.

Cai, Y. H. (2002). Teacher's Job Performance: The Construction and Influence Factors Research. Unpublished Doctorial Dissertation, Beijing: Beijing Normal University.

Coleman, V. I. (2000). Investigation of the Underlying Structure of the Contextual Performance Domain. The Science and Engineering, 58, 4499.

Conway, J. M. (1999). Distinguishing Contextual Performance from Task Performance for Managerial Jobs. Journal of Applied Psychology, 84, 3-13. http://dx.doi.org/10.1037/0021-9010.84.1.3

Fan, J. L. (1997). Impetus for Action: A Cultural Analysis of Justice and Organizational Citizenship Behavior in Chinese Society Administrative. Science Quarterly, 42, 421-444.

Johnson, J. W. (2001). The Relative Importance of Task and Contextual Performance Dimension to Supervisor Judgments of Overall Performance. Journal of Applied Psychological, 86, 984-996. http://dx.doi.org/10.1037/0021-9010.86.5.984

LePine, J. A., \& Van Dyne, L. (2001). Voice and Cooperative Behavior as Contrasting Forms of Contextual Performance: Evidence of Differential Relationships with Big Five Personality Characteristics and Cognitive Ability. Journal of Applied Psychology, 86, 326-336. http://dx.doi.org/10.1037/0021-9010.86.2.326

Van Scotter, J. R., \& Motowidlo, S. J. (1996). Interpersonal Facilitation and Job Dedication as Separate Facets of Contextual Performance. Journal of Applied Psychology, 81, 525-531. http://dx.doi.org/10.1037/0021-9010.81.5.525

Wang, M. H. (2006). The Study of Content and Structure of Employees’ Organizational Socialization and Its Relationships with Other Related Variables. Doctorial Dissertation, Guangzhou: Jinan University.

Zhou, Z. H., \& Wang, E. P. (1999). The Criterion Study of Personnel Psychology. Journal of Developments in Psychology, 7 , 53-57. 